\title{
The Nature and Therapeutic Implications of the Extraordinary Experiences of the Bereaved
}

\author{
Louis E. LaGrand, Ph.D., CT \\ State University of New York at Potsdam \\ Loss Education Associates, Venice, FL
}

\begin{abstract}
The extraordinary experiences (EEs) of the bereaved are prevalent phenomena in which claimants believe they have received a spontaneous contact from a deceased loved one or a divine being. These subjective experiences consistently bring healing and comfort to those who are mourning the death of a loved one. Yet EEs remain cloaked in secrecy and receive relatively little publicity due to the controversial nature of the experience. Mourners already dealing with the burdens of grief are reluctant to trumpet their experience and risk being stigmatized, sometimes by the caregivers who should be utilizing the opportunity to help them adapt to their loss. This article highlights the types of contacts reported, messages claimants believe are received, changes in death perceptions, and the therapeutic potential of the experience for coping with the death of a loved one. Much of the material is based on a workshop given by the author throughout the United States.
\end{abstract}

KEY WORDS: extraordinary experiences; after-death contacts.

Mystical and extraordinary personal experiences have been occurring since the dawn of human history (Cardeña, Lynn, and Krippner; 2000; Devers, 1997; Romanoff and Terenzio, 1998; Treece, 1995). However, there is also a parallel history of ignoring, falsely labeling, or even denying their existence (Radin, 1997; Tart, 1997). Of all such unexplainable phenomena, arguably the least publicized although among the most influential in life, are the extraordinary experiences

Louis E. LaGrand, Ph.D., CT, is Distinguished Service Professor Emeritus at the State University of New York at Potsdam. Reprint requests should be addressed to Dr. LaGrand at Loss Education Associates, 450 Fairway Isles Drive, Venice, FL 34285; e-mail: BL450@msn.com. 
(EEs) of the bereaved. These events involve the belief by those mourning the death of a loved one that they have received a spontaneous sign or message from the deceased or a divine being.

The key word is spontaneous: the experience is not invoked or a product of psychic intervention. According to claimants, it appears to originate from an outside source and usually happens when the person is composed and not thinking of the beloved. However, many support persons and counselors suggest that mourners pray for a sign that their loved ones are safe in another existence (Duminiak, 2004). There is even a website for those seeking prayer assistance in this regard (www.geocites.com/adcfriends).

The dismissal of unexplainable experiences as symptoms of psychopathology appears to be especially prevalent when they occur to those who are mourning the death of a loved one or when loved ones who are dying report seeing people who have predeceased them. Not unlike the bereaved, the dying are grieving the loss of their worlds and their loved ones. Surprisingly, in some cases of death bed visions, the dying person who is never told of the death of a friend or relative, reports a visit from that deceased individual (Grosso, 2004).

The frequent pronouncement to explain away such events is that the claimant is in a disorganized and confused state awash in emotion, and is therefore subject to hallucinations, illusions, or other forms of confused thinking (Berger, 1995; Parkes, 1987; Raphael, 1983; Rees, 1971; Staudacher, 1987; Woods, 1998). Conversely, others suggest that EEs consistently result in expanded awareness, often a shift in values and beliefs, as well as a reduction in anxiety associated with grief (Drewry, 2002; LaGrand, 1997b, 2001; Targ, 2001; White, 1997; Woods, 1998).

Although mystical and psi-type events have conveniently been labeled as impossible in order to preserve the existing scientific paradigm, at root their etiology will always remain a mystery. No one on either side of the issue possesses incontrovertible proof of origin, although the plethora of well documented cases of contact give us pause and should not be ignored (Fontana, 2005; Grosso, 2004; Haraldsson, 1987; Stevenson, 1982). Yet mystery is an integral part of existence and positive mental health, and will continue to pose more questions than provide answers (Chesterton, 1908; Ensley, 1997; Raymo, 1987, 1998). The wisdom of the extraordinary calls claimants and their caregivers to greater consciousness of the role of mystery and its unifying properties in the world at large. Significantly, it often leads to action, and for those coping with the death of a loved one, to take the difficult road to restoration. 


\section{Transformation Through Extraordinary Experiences}

Motivation to reinvest in life is often due to the belief that the deceased has reached out to give comfort. The dead are commonly viewed as consoling and providing solace to survivors and the dying (LaGrand, 2001; Treece, 1995; Woods, 1998). Here is an example from a man whose son was killed in an automobile accident just days after his graduation from the Ohio State Highway Patrol Academy:

The crying and pain that we went through I would not wish on anyone under any condition. The support of many helped, but ultimately we still had a tough road ahead. The crying and grief can come up suddenly by seeing a picture, hearing a song, or seeing a friend. The longing that one has is truly difficult, especially when one has such a close and loving family. I had always believed there was a hereafter and that something still existed after death. But without proof, who knows?

Well, let me tell you, proof was on its way! On the morning of February 4, 1998, forty-five days after Eric's death in a car accident, I awoke at 6:45 a.m. along with my wife Marilyn. She got up to prepare for work as she leaves earlier than I, so I got up and prepared my computer for the day's work. Then I sat down on the bed waiting for Marilyn to finish drying her hair in the bathroom. At 7:15 Marilyn turned off the hair dryer signaling she was finished. I got up off the bed - fully awake and up for one-half hour. My mind was clear. I was not crying and not under any stress. As I took my third step toward the bathroom, I felt a tremendous squeeze and hug on both sides of my body which stopped me in my tracks. Eric appeared right in front of my face, smiling, and the whole room was full of energy. It's like the molecules, atoms, and air are all moving at a tremendous speed. It was forceful, explosive, loving, highly energized - the most exhilarating experience that I have ever had!!

I hugged Eric. I was hugging an energy force not a real physical body. I kissed him on his right cheek and felt his beard/whiskers on my lips. He was moving so fast that I believe he had just passed through the bathroom and barely missed his mother. It was as though he was flying through the house. My mind was ecstatic, lucid, fully awake and aware of what was happening. I could see the tremendous love in the complete environment that Eric brought with him. I knew this was real, on purpose, planned by Eric as I could never have written or wished the events in this spontaneous experience. The force field, aura, and energy surrounding Eric was so strong and charged that it pushed me back onto the bed. It was not Eric's hands pushing me as I could not feel them on me. It was a moving energy of molecules that were traveling at an unbelievable rate of speed. As I had my arms around Eric, his image and I were falling toward the bed. He told me telepathically, "I love you Dad. I love you Mom." His lips did not move. As we fell, he rolled over the top of me and 
I could see his whole body. He rolled right into the spot where we had placed his police uniform, leather coat, and hat in the middle of the bed. Marilyn and I placed his clothes there and slept with them for a week after his death because as a baby he and the dog would climb in bed with us. They would wrestle, Eric would grab the dog's hair, and be pulled off the bed. The clothes let us again relive his presence and we could cry and mourn over him together. If I were asked to write a request for an after-death visit I would never have written this-it was wonderful. Eric Zimmerman was in full and complete control for the ten plus seconds of his visit. He let me know positively that he was still alive in a fast moving energy force, in a different plane or dimension, which he was controlling with complete happiness and everlasting love. I saw a view of eternity and believe me it is a wonderful, loving, totally encompassing, joyful world.

I sell pharmaceuticals for a living. I could never reproduce the high, loving understanding, elated, explosive, forceful, molecular moving, ten plus seconds with any drug or medicine!!! Never, never, never. I have tried to relive that experience, but I cannot raise my mind to a fraction of the degree of clearness, love, excitement or energy level that I was given by Eric's visit. Thank you son for allowing your Dad the opportunity to know beyond a doubt that we exist beyond the physical body and that a better life is yet to come to all of us. (LaGrand, 1999, pp. 152-153)

Notice the conviction in the belief that his son lived on, in the love that inspired the visit, and the comfort received from the supposed contact. To the recipient, the experience is real (Barbato, Blunden, Reid, Irwin, and Rodriguez, 1999; LaGrand, 1997a; Targ, 2001; White, 1997). Such belief opens the way to using it in a variety of ways for an adaptive outcome.

I use the term extraordinary experiences, although they are quite ordinary, in order to separate them from paranormal phenomena of various kinds (such as mediumship, telepathy, precognition, and clairvoyance) that are commercialized on television and radio. EEs are specifically a life-changing part of the mourning process for many, and need to be honored and given their own specific identity.

It is estimated that 70 million people from all walks of life have experienced the extraordinary when mourning. Melvin Morse suggested that a majority of widows and parents who have lost children have visions of the departed within a year of the death (Morse and Perry, 1994). Andrew Greeley (1987) in a national opinion research poll found that 42 percent of the US population answered in the affirmative to the question: "Have you ever felt you have been in contact with someone who died?" Widows and widowers commonly report evidence that suggests their counterparts have survived (Gallup and Proctor, 
1982). It is clear that a large percentage of the grieving population have the experience (Cardeña, Lynn, and Krippner, 2000).

Not to be overlooked, children especially report contacts with deceased loved ones and divine beings that influence the way they perceive the world and make choices, and the experience leaves them with a deep reverence for life (Hart, 2003; Lawson, 2003). Here is a recent example from a 41-year-old woman I interviewed:

In November of 1966, I was nine years old, approaching my tenth birthday. I was the youngest of four children. We lived in Queens, New York. Since his early thirties, my father had been plagued with a "heart condition" and had had several very traumatic coronary events. When he died in 1966, he was forty-nine years old.

My Extraordinary Encounter begins with a premonition - one I believe was shared by my father and myself. On November 29, 1966, just four days after Thanksgiving, my mother woke me up for school as usual. In September, I had been "skipped" from the fourth to the fifth grade and I was very pleased with myself and very excited by the new challenging work. I had always loved school - loved to read and the sunny, bustling classroom was such a relief from the usual somber mood of my house. I might add that I was pretty much a docile child and had somewhere along the way taken up the role as peacemaker in the household. This is why it shocked even me when I refused to go to school that day. My mother scolded and argued but I wouldn't be budged. I didn't even have a reason; I just knew that I couldn't go to school that day. The feeling was overwhelming and I was willing to tempt my mother's anger to succumb to the feeling. Finally, my mother literally threw her hands up and left the house, late for work. Like any nine-year old, I proceeded to take full advantage of the situation and prepared to spend the day goofing off.

At some point, I did go downstairs; I think I was still in my pajamas. I remember glancing at my parents' bed and noticing that my father was still in bed. I think the notion had occurred to me that he ought to be up by now. As a child, however, you don't generally question what grownups do or don't do. So if it did occur to me that he was sleeping unusually late, I'm sure it would have been in a rather peripheral and matter-of-fact way.

Quietly at first and then quite distinctly, a sound started coming from my father's bed. A gurgling - long and drawn out. I remember being thunderstruck. The sound was so unreal - so unlike any sound I'd ever heard a person make before. Of course, I now know it was the "death rattle," but at the time I only knew it was something consequential - I honestly wasn't sure what. I felt torn - I felt that some action was required of me but I didn't know what. I felt helpless and scared. I continued to eat the sandwich I had made as though it would forever ground me to life as I had known it before. I froze. I ignored the sound as long as I could. Finally, it grew quiet. I don't know how long I sat there in silence; I think it was a long time. 
Eventually, I somehow propelled myself out of the chair and tentatively walked over to my father.

In a moment that will always be frozen in time, I had what I have now come to understand as an after-death communication. Slowly and fearfully, I moved toward my father. He was on his back on the inside half of my parents' double bed. I remember the fingers of his right hand, so like my own, delicately curled up as if in sleep. I had to reach across the entire left side of the bed to touch him - but somehow despite my earlier fears, I was compelled to touch him. I remember reaching out with my right hand and touching his right arm just below the shoulder.

In that instant, two things happened. My hand reached out and touched his arm and my brain acknowledged that he was dead. The bare flesh of his upper arm was cold. Even at nine, I registered this as death. This was colder than a person should ever be. In the instant the feelings of panic should have overtaken me - this was my father and he was as cold as the kitchen floor - I was overtaken by a sense of utter peace. It was almost as though he were waiting for my touch. In that instant (I don't think my hand had even left his flesh yet) I had a clear communication from my father. His message was a simple one - it came and it went in a flash: "Everything will be all right." Simple and succinct, yet a moment in time and a message that struck my very soul with a profundity the likes of which I have never been able to reexperience in my entire lifetime. This message conveyed to me a very general sense of "okay." Not just that I would make it through this crisis. Not just that he was okay. Not just that my lifetime would be okay. "Everything" - every little thing in the universe was okay. Everything as we knew it and perceived it was "all right." It was how it was meant to be. And then he simply left. I would have to say that person to person, regardless of our relationship and certainly our age difference - our levels of experience - it was on joyful wings that he left.

One of the details that has always stood out in my mind about this experience and has attracted me to many of the accounts of neardeath that I have read is this: My father's voice - and I know it was his voice - did not have its source in or even near his body. Rather, his voice very clearly and distinctly came from a spot where the right angles of the walls met the ceiling in the corner of the bedroom. My father spoke to me from a point that was many feet away from his body. Naturally, many times over the years, I have relived this moment over and over in my mind.

I have never again sensed, heard, or felt the presence of death or foreboding that I felt in 1966 - the day my father died. Nor have I felt the perfect joy and peace that I experienced on that same day. My father, to my knowledge, has never again tried to contact me, nor has any other soul. Yet, based on my experience, more than thirty years ago, I believe that, in fact, we do survive after death in a way that I can only describe as blissful.

Since this experience, I have grown up to be a normal well-rounded woman. In my forty years, I have to say that the most pronounced change in my life is that I have no fear of death. I know without 
question that after we leave this earth, we continue to live in a different form. This belief is so long instilled in me, that I can't even imagine a person going through life questioning whether there is life after death. (LaGrand, 1999, pp. 143-148)

This life-changing event not only assisted in the management of grief, it formed the basis for a strong belief in an afterlife. Regrettably, many of the reports from children are dismissed as overactive imaginations or daydreams (Hart, 2003). Much learned from these experiences is not reinforced by significant adults, and children are forced to interpret their experiences with no preparation or guidance.

As a grief counselor, workshop presenter, and leader of support groups for suicide survivors, widows and widowers, I am privy to the personal and sometimes mysterious experiences of a wide variety of people. And as occurs in many forms of research on human behavior, I sometimes have to rely heavily on human testimony recognizing the risks of exaggeration and faulty memory (Fontana, 2005). On the other hand, many witnesses can be quite accurate in describing their supposed contact. Typically, according to claimants, EEs spawn personal and/or spiritual growth, reduce existential fear, and generate new perspectives and purpose in life through the questions they suggest and the obvious answers provided.

Many EEs result in major shifts in worldviews as well as in the philosophical stance of those receiving them. Brian Inglis (1990), Ken Anderson (1995), and Deepak Chopra (2003) argued that even socalled coincidental or synchronistic events provide insights and guidance for those who pay attention to them. For claimants reporting extraordinary experiences, the consistent overwhelming questions that present are: Where do I go from here? What will I do with my experience? How will I put to use what I have learned?

\section{The Multidimensional Realms of the Extraordinary}

Over the past 25 years in my interviews with claimants and discussions with counselors I have classified the extraordinary experiences of the bereaved into the following fourteen categories:

1. the intuitive or sense of presence experience (sometimes reported accompanied by a telepathic or mental message); 
2. the visual or apparitional presence (which may be a facial or full body appearance);

3. the auditory or voice experience (which also includes telepathic communication for some claimants);

4. the olfactory or sense of smell experience (such as flower scents, pipe smoke, perfumes, or colognes);

5. the tactile or sense of touch experience (in which claimants believe they have been embraced, kissed, or touched on the arm or shoulder by the loved one or a divine being);

6. unusual behavior of birds or animals (such as appearing unexpectedly in places or at times when never before seen and being associated in various ways with the loved one);

7. symbolic experiences (such as rainbows presenting at unusual times, butterflies appearing repeatedly and staying with the survivor, and finding objects associated with the deceased);

8. third-party experiences (in which the claimant receives a sign or message that comes through a third person, either child or adult, who has the EE);

9. fourth-party experiences (in which the claimant receives a sign or message that comes through two other people);

10. visitation dreams (vivid, unforgettable dreams, as in the "big dream" described by Carl Jung);

11. out-of-body experiences (in which the claimant has an outof-body experience and sees the departed loved one);

12. psi kappa (objects move, a clock stops or starts at the moment of death, or lights or other electronic equipment go on and off as a sign);

13. synchronicities (meaningful coincidences pairing something associated with the deceased loved one with an unexpected physical event); and

14. crisis apparitions or sense of presence (in which visual appearance or sense of presence of the loved one is experienced before the survivor has been notified of the death).

The sense of presence and dream state EEs are most commonly reported (LaGrand, 1999; Wright, 1998). Clearly, all of the above are open to skeptical analysis, as they should be. Science can save us from superstition and magical thinking. At the same time, we must be vigilant that dogmatic science does not minimize the credibility of unexplainable human experience or our sense of wonder and awe at the mysterious universe. At the very least, therapists and caregivers 
should not discredit these experiences simply because they challenge their own worldviews (LaGrand, 2001; Weiss, 1988). I hasten to add that the most skeptical responses often come from those who have not had an EE. I know several professional counselors who harbored grave doubts about the veracity of extraordinary experiences as reported by clients - until they were suddenly face to face with the extraordinary after the death of a husband or family member. The nature of their professional practices took an abrupt turn as they began to see the therapeutic value and personal meaning that the contact could have on the grief process.

Nevertheless, the issue to confront is not whether these profound subjective experiences can be proven real or unreal, although that is an intriguing question. Obviously, we have to be reasonably sure that the claimant was not severely agitated or suffering from deep emotional trauma at the time of the event. The real issue is that a large number of claimants report the experience though not expecting it, receive solace and comfort from it, and believe in its authenticity - all of this, in the absence of any psychiatric disorder. Furthermore, and a critical adjunct to grief work, the anxiety associated with the question of whether the loved one lives on is reduced or eliminated (LaGrand, 1997b; Linn, 1991).

\section{Messages, Meanings, and Changes}

It follows that most claimants are not merely convinced of the authenticity of the experience; they take to heart the messages received, make major changes in their worldviews, and find new meaning in life and death. Finding meaning in the death of a loved one through an EE can be a profound healing experience as one deals with the eternal questions of Who am I? Why am I here? And what happens after we die? Although commonly overlooked, meaning has a strong physical impact on a person at the cellular level (Dossey, 1991) as well as an emotional one. One's health can be positively affected by a contact. Meaning therapy is indeed important in grief work. Not infrequently, claimants are able to take their $\mathrm{EE}$, use it to revise their assumptive world, and weave the new insights received into a coherent framework of continuity, direction, and life purpose. In particular, and most significantly, continuing love is often seen as the driving force behind the contact (LaGrand, 2001; Wright, 2002). 
Messages received may be explicit, implicit, telepathic, or implied as interpreted by the claimant. Some give advice ("Go home and live"). Others are inspirational ("He's saying I can get through this"). Most are supportive ("My father wanted to comfort me"). Specifically, there are a number of repeating themes that present themselves in terms of messages and belief changes. Claimants are convinced the loved one lives on and the deceased has knowledge of their plight as survivors. One of the most frequently cited themes is a loss of the fear of death. Many claimants report there is nothing to fear and it brings a sense of relief, freedom, and anticipation. The anticipation is focused on a second common belief change: there will be a reunion with the deceased loved one. This is followed by the belief that consciousness must survive bodily death. The knowledge that life goes on, albeit in a different form, can be the most important factor in the reconstruction of one's life after the death of a loved one. Presumption and despair is often replaced with optimism and hope.

Not infrequently, the claimant's perception of the health of the one dearly loved may also undergo a major change. He or she is perceived as whole and happy again, no longer incapacitated or suffering from disease. This is especially clear when the claimant reports a visitation dream or seeing the deceased in a vision or apparition. Relief at the awareness of wholeness is another motivating force in accepting the death and beginning the task of reinvesting in life.

Importantly, it is not unusual for the death of a loved one to challenge the spiritual beliefs of survivors and precipitate a spiritual crisis (Marrone, 1999; Martin and Elder, 1993). Yet spiritual traditions are exceptionally valuable resources in coping with life and death (Targ, 2001). And spiritual surprises abound through the EE, bringing support and reinforcement. The EE often induces a paradigm shift that is spiritually oriented (Devers, 1997). The spiritual significance of the EE is this: faith in something greater than the self is suddenly reawakened. Religious beliefs are also affected. It is not unusual for those who have drifted away from the religious practices of earlier years to find new interest in returning to their houses of worship.

Finally, the extraordinary experience often results in claimants seeing life and their life mission with a different perspective (Devers, 1997; LaGrand, 1997a). Life purposes are reassessed. It is not unusual for the bereaved to be motivated to reach out to those who are in special need, to become more compassionate, or to take up a task that might help their community and perpetuate the memory of the beloved. All of the above changes are new beginnings many people 
make throughout life, but the EE motivates the shift for the claimant by reigniting a deep sense of belonging.

\section{Therapeutic Implications}

The transformative potential of the EE in coping with the changes imposed by the death of a loved one has long been ignored (LaGrand, 1997b). There are four specific prerequisites for intervention using extraordinary experiences: disciplined familiarity, routine inquiry, techniques for validation, and knowledge of the claimant's belief system.

Understanding the nature of the phenomenon, particularly types of experiences, messages believed received, its meaning to the survivor, and the potential for use in coping with loss and change, is essential. It suggests reading a variety of books written for the general public, recent studies of the effects of EEs on claimants, and familiarity with various spiritual traditions. Talking to those who claim these encounters as well as colleagues, bereavement coordinators in hospices, and support group providers will add immeasurably to an awareness of the diversity of the experience and the many ways it can be interpreted by the bereaved.

Although some caregivers never ask, in most protocols, routine inquiry about extraordinary experiences is part of the intake interview. I recommend that this practice should not be strictly adhered to for the following reason: some claimants believe the event is too personal to share with anyone they do not know or trust. Consequently, some will reply in the negative when asked if they have had what they believe to be a contact from the deceased. Of course, others at intake will willingly respond. While it is at best an intuitive call, in some cases an inquiry may have to wait until the third or fourth meeting with the client.

Understanding the loss experience from the claimant's unique perspective is essential in facilitating the grief process (Rando, 1993) and it is equally essential in terms of the effective use of the extraordinary experience. Significantly, it is the belief system particularly the meaning of the message received - that must be thoroughly understood and given highest priority. As we have seen, a different belief about death changes everything for the claimant. Specific beliefs about contents, origin, and why the event happened need to be uncovered and discussed, with reassurance given that the 
experience is normal (Hastings, 1983). This will set the stage for using the EE in a variety of therapeutic ways. It is their grief, their experience, their interpretation - and most important - their belief, not ours. In the final analysis, they and they alone are responsible for managing their grief work. Thus, openness on the part of the support person, and allowing the claimant's belief system to predominate is essential for establishing therapeutic use of the experience.

In addition, the need for acceptance and validation of the event may be essential for the claimant who in some cases may question his or her sanity and feel threatened by what caregivers or friends might think of the disclosure (Drewry, 2002; Hastings, 1983; Hoyt, 1980; Peterson, 2001; Whitney, 1992). Others need assistance in reconciling the experience with their scientific worldview (Devers, 1997). To facilitate validation and help claimants reach a decision on authenticity, if any doubt surfaces, I recommend the following questions:

- Is this the kind of thing your loved one would do if he or she could?

- Do you feel the experience has involved giving and receiving love?

- What is your deep intuitive feeling about the event?

- Did the experience bring peace?

I emphasize the importance of peace with all clients, often suggesting that if the claimant feels more peaceful he or she is being led by something greater than the Self. We then discuss the importance of considering peace or conflict in decision-making, but especially in matters involving adapting to the current loss.

\section{Cognitive and Intrapsychic Processes of Grief}

Therese Rando (1984, 1993) has identified several cognitive and intrapsychic processes of grief that often do not receive the attention necessary to facilitate the normal processing of the loss experience. Extraordinary experiences are ideal vehicles through which these processes can be discussed and acted upon. They include, but are not limited to, forming a new identity, establishing a new relationship with the deceased, and withdrawing emotional energy from the deceased to reinvest in new life pursuits. This in no way implies the complete withdrawal of emotional investment in the deceased. On the contrary, a new relationship with the deceased is healthy and is built on memories, traditions, and what was learned from the relationship when the deceased was still living. Furthermore, establishing a new 
relationship is a vehicle for assessing values, adapting to the physical absence of the beloved, finding comfort, and giving meaning (LaGrand, 2001; Vickio, 2000).

Many grief researchers have challenged the traditional theory of relinquishing attachment to the deceased in favor of altering and establishing a new bond (Balk, 1996; Conant, 1996; Klass, Silverman, \& Nickman, 1996; Romanoff and Terenzio, 1998; Stroebe, Gergen, Gergen, and Stroebe, 1996; Worden, 1991). Discovering a better way to have a relationship with the deceased loved one is a legitimate reason for therapy (Rando, 1993).

Interestingly, a theme apparent in many dream visitations reported by claimants is that the deceased takes for granted that the relationship is ongoing while the claimant may be struggling with the concept (Kennedy, 1997). The extraordinary experience often helps the claimant understand this idea of a new relationship and facilitates the healthy completion of the cognitive and intrapsychic processes.

Although silence is golden in the counseling setting, a thorough discussion of the three processes within the context of the EE is necessary and should focus on the premise that the experience implies the following: the loved one is in another realm, is still caring, that a relationship based on memory and tradition is appropriate, and that the claimant is a different person entering a new life without the loved one. Emphasis is on a new life, which means the necessity to establish other rewarding relationships, develop new interests and strengthen identity, and reinvest emotional energy in rewarding pursuits.

Often new relationships are established through support groups where the EE is a topic of conversation and in meeting others who have had extraordinary experiences. Such actions promote identity building and shifts in emotional investment centering on the experience. All of the above are based on using the motivation of the contact from the loved one as a sign that these tasks are both appropriate and expected. The belief in the extraordinary experience allows for a key question to be presented to the claimant: "Your loved one is okay, has told you so, and wants you to be okay too. What do you think he or she is asking you to do?"

Depending on the type of experience reported and the message or messages the claimant believes was sent, the EE can be used to adapt to a new life by way of establishing new routines and reducing anxiety caused by the loved one's physical absence. Here are several specific ways to use the experience in dealing with the changes imposed by loss. Again, using the extraordinary experiences of the 
bereaved as a tool to aid in coping with the death of a loved one is predicated on the assumption that the claimant is the expert on his or her grief and grief work. Here is a short list of possibilities for using the experience:

1. Suggest finding a word that typifies the EE and the attributes of the deceased loved one (such as compassion, love, gratitude, care, or service). Discuss with the claimant how that special word can be the basis for a plan to put into action as a memorial to keep the loved one's memory alive. Introduce the idea that the EE is a seed of hope to be cultivated and used as a bridge to a new life in which the deceased will always be remembered, and in times of doubt and despair, a way through will always be found.

2. Discuss what the loved one has taught the claimant through the gift of the EE that can be passed on to others in the family and outside of it. This lesson (of caring, love, concern, giving, thinking of others, and so on) plus the loved one's finest qualities can be highlighted as a gift to all. Discuss what specific behaviors would best represent the lesson or lessons taught by the EE.

3. Just as touching the inscribed name of a loved one on the Vietnam Veterans Memorial in Washington brings meaning and comfort, so too can touching or holding a symbol, object, or piece of clothing associated with the EE. Discuss creating a word picture or symbol representing the EE to be used as a reminder or motivator in establishing a new routine or to give comfort and guidance. The symbol can be cut from a picture in a magazine, drawn, or crafted by the claimant. It could be a possession of the deceased or something given to the claimant by the deceased that was a part of or a reminder of the EE. The object can be put in Lucite or mounted. Choose an appropriate place to display it so it can be used as needed.

4. Whenever there is unfinished business or conflict between the survivor and the deceased, suggest that the EE is given on the assumption that all transgressions have been forgiven. The EE can be looked at as an olive branch, that the loved one forgives or seeks forgiveness, and sees the earthly conflict from a more positive perspective.

5. Suggest having a drawing or painting made of the EE and give it a name. Have it framed and placed in an appropriate place in the home to be used as a reminder to be thankful and look for other blessings in life that are easily overlooked. 
6. Establish the specific message the claimant has received from the EE. Then ask if the person would like to respond to the gift and send a message of thanks or remembrance to the loved one. Have that message written or typed and kept in a place where it will be frequently seen. The message could also be inscribed or printed on a cup or glass as a warm reminder each time it is used that a loving relationship will always exist.

7. Consider creating an affirmation based on the message of the EE, such as, "I am always connected and loved by those who are important to me," or, "I will stay positive." The affirmation can be repeated at any time or place that the claimant feels is appropriate. It can also be crafted and placed on the dashboard of a car or at one's office or workplace. Have several copies made for use in various locations.

8. EEs can also be used in creating rituals of transition, continuity, reconciliation, or goodbye. A formal or informal ritual can be created based on the EE for the purpose of highlighting a specific memory about the loved one. The ritual can be used on a daily basis, on the anniversary of the death or the EE, or on key dates during the year. An informal ritual based on the EE could also be created that emphasizes a new routine the claimant is trying to establish.

\section{The Challenge}

For more than two decades I have been involved in studying one aspect of the mosaic of the extraordinary: those experiences that occur to the bereaved after the death of a loved one. The results of these spontaneous encounters have characteristically inspired the claimant to heal emotional wounds, look at life with a new perspective, and often find the most cherished prize of all, peace of mind. Such changes have occurred due to the learning that takes place through experiencing the extraordinary and believing the essential messages or their implications. In essence, extraordinary experiences are the seeds of change in relationships with others, with those who have died, and with the world at large. In short, they enhance the quality of life.

Much of the transformation that takes place is the natural process that accompanies believing in and internalizing the experience. Regrettably, it is sometimes buried or suppressed and the claimant is 
fearful of bringing it to the attention of the therapist (Targ, 2001), or the work of using it is too often attempted in isolation and without support. The challenge of all support persons is to develop greater awareness of the large numbers of mourners who have the experience, recognize its potential for adapting to the death of a loved one and for reinvesting in life, and work on minimizing personal biases for or against it. Then let us learn to validate and encourage the claimant to embrace the experience as a gift, and creatively utilize it in a healthy manner.

\section{References}

Anderson, K. (1995). Coincidences: chance or fate? London, England: Blanford.

Balk, D. (1996). Attachment and the reactions of bereaved college students: A longitudinal study. In Klass, D., Silverman, P., and Nickman, S. (eds.), Continuing bonds: new understandings of grief (pp. 311-328). Washington, DC: Taylor and Francis.

Barbato, M., Blunden, C., Reid, K., Irwin, H., and Rodriguez, P. (1999). Parapsychological phenomena near the time of death, Journal of Palliative Care, 15, 30-37.

Berger, A. (1995). Quoth the raven: Bereavement and the paranormal, Omega, 31, 1-10.

Cardeña, E., Lynn, S., and Krippner, S. (2000). Anomalous experiences in perspective. In Cardeña, E., Lynn, S., and Krippner, S. (eds.), Varieties of anomalous experiences: examining the scientific evidence (pp. 3-22). Washington, DC: American Psychological Association.

Chesterton, G. (1908). Orthodoxy. London, England: John Lane.

Chopra, D. (2003). The spontaneous fulfillment of desire: Harnessing the infinite power of coincidences. New York, NY: Harmony Books.

Conant, R. (1996). Memories of the death and life of a spouse: The role of images and sense of presence in grief. In Klass, D., Silverman, P., and Nickman, S. (eds.), Continuing bonds: new understandings of grief (pp. 179-196). Washington, DC: Taylor and Francis.

Devers, E. (1997). Goodbye again. Kansas City, MO: Andrews and McMeel.

Dossey, L. (1991). Meaning and medicine. New York, NY: Bantam.

Drewry, D. (2002). Purported after-death communication and its role in the recovery of bereaved individuals: A phenomenological study. Unpublished dissertation, California Institute for Human Sciences, Encinitas, CA.

Duminiak, C. (2004). God's gift of love: After-death communications. Philadelphia, PA: Xlibris.

Ensley, E. (1997). EHEs and the sacred. In White, R. (ed.), Exceptional human experiences: Background papers II (pp. 1-2). New Bern, NC: The Exceptional Human Experience Network.

Fontana, D. (2005). Is there an afterlife? A comprehensive overview of the evidence. Hants, England: O Books.

Gallup, G., and Proctor, W. (1982). Adventures in immortality: A look beyond the threshold of death. New York, NY: McGraw-Hill.

Greeley, A. (1987). Mysticism goes mainstream. American Health, 6, 47-49.

Grosso, M. (2004). Exploring the next world now. New York, NY: Paraview Pocket Books.

Haraldsson, E. (1987). The Iyengar-Kirti case: An apparitional case of the bystander type. Journal of the Society for Psychical Research, 54, 64-67. 
Hart, T. (2003). The secret spiritual world of children. Maui, HI: Inner Ocean Publishing.

Hastings, A. (1983). A counseling approach to parapsychological experiences, Journal of Transpersonal Psychology, 15, 143-166.

Hoyt, M. (1980). Clinical notes regarding the experience of "presences" in mourning. Omega, 11, 105-111.

Inglis, B. (1990). Coincidence: a matter of chance - or synchronicity. London, England: Hutchinson.

Kennedy, A. (1997). Your loved one lives on within you. New York, NY: Berkeley Books.

Klass, D., Silverman, P., and Nickman, S. (eds.). Continuing bonds: new understandings of grief. Washington, DC: Taylor and Francis.

LaGrand, L. (1997a). After death communication: Final farewells. St. Paul, MN: Llewellyn.

LaGrand, L. (1997b). Are we missing opportunities to help the bereaved? The Association for Death Education and Counseling Forum Newsletter, 23, 5.

LaGrand, L. (1999). Messages and miracles. St. Paul, MN: Llewellyn.

LaGrand, L. (2001). Gifts from the unknown. Lincoln, NE: iUniverse.

Lawson, L. (2000). Visitations from the afterlife. San Francisco, CA: HarperSanFrancisco.

Linn, E. (1991). Premonitions, visitations, and dreams of the bereaved. Incline Village, NV: Publisher's Mark.

Marrone, R. (1999). Dying, mourning, and spirituality: A psychological perspective. Death Studies, 23, 495-519.

Martin, K., and Elder, S. (1993). Pathways through grief: A model of the process. In Morgan, J. (ed.), Personal care in an impersonal world: A multidimensional look at bereavement (pp. 73-86). New York, NY: Baywood.

Morse, M., and Perry, P. (1994). Parting visions: Uses and meanings of pre-death, psychic, and spiritual experiences. New York, NY: Villard Books.

Parkes, C. M. (1987). Studies of grief in adult life. Madison, CT: International Universities Press.

Peterson, B. (2001). Psychology and ghosts: A historical review and phenomenological analysis of apparitions in the context of mourning. Unpublished doctoral dissertation, Massachusetts School of Professional Psychology, Boston, MA.

Radin, D. (1997). The conscious universe: The scientific truth of psychic phenomena. San Francisco, CA: Harper Edge.

Rando, T. (1984). Grief, dying, and death: Clinical interventions for caregivers. Champaign, IL: Research Press.

Rando, T. (1993). Treatment of complicated mourning. Champaign, IL: Research Press.

Raphael, B. (1983). The anatomy of grief. New York, NY: Basic Books.

Raymo, C. (1987). Honey from stone: A naturalist's search for god. New York, NY: Dodd, Mead.

Raymo, C. (1998). Skeptics and true believers. New York, NY: Walker.

Rees, W. D. (1971). The hallucinations of widowhood. British Medical Journal, 4, 37-41.

Romanoff, B., and Terenzio, M. (1998). Rituals and the grieving process. Death Studies, $22,697-711$.

Staudacher, C. (1987). Beyond grief. Oakland, CA: New Harbinger Publications.

Stevenson, I. (1982). The contribution of apparitions to the evidence for survival. Journal of the American Society for Psychical Research, 76, 341-357.

Stroebe, M., Gergen, M., Gergen, K., and Stroebe, W. (1996). Broken hearts or broken bonds? In Klass, D., Silverman, P., and Nickman, S. (eds.), Continuing bonds: new understandings of grief (pp. 31-44). Washington, DC: Taylor and Francis.

Targ, E. (2001, Fall). Who's to say who's nuts? Spirituality and Health, p. 8.

Tart, C. T. (ed.). (1997). Body, mind, spirit: Exploring the parapsychology of spirituality. Charlottesville, VA: Hampton Roads. 